\title{
BIRC7 and STC2 expression are associated with tumorigenesis and poor outcome in extrahepatic cholangiocarcinoma
}

\author{
Jiequn Li \\ Second Xiangya Hospital \\ Zhulin Yang ( $\sim$ yangzhulin8@outlook.com ) \\ Secong Xiangya Hospital https://orcid.org/0000-0001-8484-1488 \\ Shengfu Huang \\ Second Xiangya Hospital \\ Daiqiang Li \\ Second Xiangya Hospital
}

\section{Research}

Keywords: Extrahepatic cholangiocarcinoma, BIRC7, STC2, Immunohistochemistry

Posted Date: March 12th, 2020

DOl: https://doi.org/10.21203/rs.3.rs-16987/v1

License: (9) (i) This work is licensed under a Creative Commons Attribution 4.0 International License. Read Full License 


\section{Abstract}

Background: Extrahepatic cholangiocarcinoma (EHCC) is a highly aggressive epithelial malignancy and has a poor prognosis for the insensitivity to therapies and difficulty in detection. Novel targets and biomarkers are urgently needed to develop for functional, diagnostic and prognostic application on EHCC.

Methods: Immunohistochemical staining technique using the EnVision antibody complex was performed on the samples obtained from 100 EHCC $₫ 30$ peritumoral extrahepatic biliary tract (EHBT), 10 EHBT adenomas and 15 normal EHBT tissues.

Results: The positive rates of BIRC7 and STC2 expression in tissues obtained from peritumoral EHBT, EHBT adenomas and normal EHBT were significantly lower than those in EHCC tissues. BIRC7 and STC2 proteins were expressed at significantly higher levels in patients with lymph node metastasis, invasion of adjacent tissues, and higher TNM stage (III and/or IV) and unable to undergo resection (biopsy only). Kaplan-Meier survival curves indicated that significantly decreased overall survival rate in patients with positive-BIRC7 or positive-STC2 expression compared with patients of negative-BIRC7 or negative-STC2 expression, respectively. Cox-proportional regression analysis demonstrated that positive-BIRC7 and positive-STC2 expression, along with poor differentiation of EHCC, tumor size $>3 \mathrm{~cm}$, lymph node metastasis, invasion of adjacent tissues and unable to undergo resection are independent prognostic factors of EHCC patients.

Conclusions $₫$ The levels of BIRC7 and STC2 expression were correlated with clinicopathological characteristics of EHCC, and positive expression of BIRC7 and STC2 are associated with progression and poor clinical outcomes of EHCC. BIRC7 and STC2 might be a potential biomarker for EHCC diagnosis and prognosis.

\section{Background}

Cholangiocarcinoma (CCA) is a highly aggressive epithelial malignancy, representing $10-25 \%$ of primary hepatic malignancies worldwide[1-3]. It is defined anatomically as intrahepatic CCA (IHCC) and extrahepatic CCA (EHCC), the EHCC is further divided into perihilar CCA and CAA of the distal bile duct. The diagnosis of EHCC is complex and usually requires a combination of clinical symptoms, imaging techniques, endoscopic techniques and cytopathological tests. Although there are promising advances in the diagnosis and treatment of EHCC, it remains challenging in clinical practice because of the insensitivity to therapies and difficulty in detection [4, 5]. In clinical practice, carbohydrate antigen 19 - 9 (CA19-9) is the most widely used tumor marker. However, it has a wide variation in sensitivity (50\%-90\%) and specificity (54\%-98\%) and is often falsely elevated in benign biliary disease and/or cholangitis, with levels falling after relief of biliary obstruction and sepsis[6, 7]. In addition, the serum marker has its own caveat that is not specific associated with EHCC. Thus, novel targets and biomarkers involved in the diagnosis, metastasis and prognosis of the EHCC are urgently needed.

Baculoviral IAP repeat-containing 7 (BIRC7), also known as Livin, encodes a member of the inhibitor of apoptosis protein (IAP) family, and contains a single copy of a baculovirus IAP repeat (BIR) as well as a RINGtype zinc finger domain $[8,9]$. The BIR domain plays a pivotal role in interacting with caspases and inhibiting apoptosis, while the RING finger domain sometimes increases anti-apoptotic activity but does not inhibit apoptosis alone $[9,10]$. Previous studies have shown that the close association between expression levels of 
BIRC7 and clinical biological behaviors, progress and prognosis of melanoma, breast, colon, prostate, bladder and gastric cancer [10-14]. The elevated expression of BIRC7 is mainly a risk factor for cancer progression, poor prognosis and resistance to chemotherapy and radiotherapy $[15,16]$. It might serve as a valuable biomarker of increased recurrence risk in prostate cancer [14]. Moreover, recent studies showed that siRNAmediated down-regulation of BIRC7 expression resensitizes tumor cells to apoptosis and chemotherapy [16, 17] and induces apoptosis in colon cancer in vitro and in vivo [18]. In short, BIRC7 might serve as a valuable biomarker and target for future diagnosis and treatment of tumor.

Stanniocalcin 2 (STC2) encodes a secreted, homodimeric glycoprotein that is expressed in a wide variety of tissues and have autocrine or paracrine functions [19]. STC2 and its homologues, STC1, may play a role in cellular calcium/phosphate homeostasis [20]. Previous studies have revealed that STC2 plays an oncogenic role in many human cancers [21-27]. The aberrant STC2 expression have certain guiding significance for the prediction, occurrence, metastasis and prognosis of gastric cancer [24], colorectal cancer [22], prostate cancer [23], breast cancer[21], laryngeal squamous cell carcinoma and [25], head and neck squamous cell carcinoma[26], endometrial cancer [27], and so on. Moreover, recent studies have found that STC2 might represent a potential marker for cancer progression, as well as a new valuable biomarker for poor prognosis [24-27].

Little is currently known about the role of BIRC7 and STC2 in EHCC. The present study aimed to investigate the clinicopathological significance and prognostic values of BIRC7 and STC in a large cohort of EHCC by immunohistochemistry.

\section{Methods}

\section{Case selection}

Between Jan 2001 and Dec 2013, 100 EHCC,30 peritumoral extrahepatic biliary tract (EHBT), 10 EHBT adenomas and 15 normal EHBT tissues were obtained at the Second and Third Xiangya Hospitals of Central South University. The patients who received chemotherapy or radiation therapy before surgery were ruled out in the study. All specimens were confirmed by two experienced pathologists who were blinded to all clinical data. The study protocol was approved by the ethical committee of Central South University. The follow-up time for EHCC was 30 months, and patients who survived more than 30 months were treated as censored cases. The clinic characteristics of EHCC were showed in Table 2. 
Table 2

Correlations of BIRC7 and STC2 protein expression with the clinicopathological characteristics of EHCC

\begin{tabular}{|c|c|c|c|c|c|c|c|}
\hline \multirow{3}{*}{ Age (year) } & \multirow[t]{2}{*}{$\mathbf{n}$} & \multicolumn{3}{|l|}{ BIRC7 } & \multicolumn{3}{|l|}{ STC2 } \\
\hline & & Pos (n, \%) & $x^{2}$ & $P$ value & Pos (n, \%) & $x^{2}$ & $P$ value \\
\hline & & & & & & & \\
\hline$\leq 45$ years & 17 & $10(58.8)$ & \multirow[t]{2}{*}{0.066} & \multirow[t]{2}{*}{0.797} & $11(64.7)$ & \multirow[t]{2}{*}{0.378} & \multirow[t]{2}{*}{0.539} \\
\hline$\nabla 45$ years & 83 & $46(55.4)$ & & & $47(56.6)$ & & \\
\hline \multicolumn{8}{|l|}{ Sex } \\
\hline Male & 61 & 37 (60.7) & \multirow[t]{2}{*}{1.376} & \multirow[t]{2}{*}{0.241} & $32(52.5)$ & \multirow[t]{2}{*}{1.971} & \multirow[t]{2}{*}{0.160} \\
\hline Female & 39 & $19(48.7)$ & & & $26(66.7)$ & & \\
\hline \multicolumn{8}{|c|}{ Differentiation } \\
\hline Well & 31 & $12(38.7)$ & \multirow[t]{3}{*}{5.560} & \multirow[t]{3}{*}{0.062} & $14(45.2)$ & \multirow[t]{3}{*}{3.064} & \multirow[t]{3}{*}{0.216} \\
\hline Moderately & 34 & $21(61.8)$ & & & $22(64.7)$ & & \\
\hline Poorly & 35 & $23(65.7)$ & & & $22(62.9)$ & & \\
\hline \multicolumn{8}{|l|}{ Tumor size } \\
\hline$\leq 3 \mathrm{~cm}$ & 62 & $32(51.6)$ & \multirow[t]{2}{*}{1.274} & \multirow[t]{2}{*}{0.259} & $35(56.5)$ & \multirow[t]{2}{*}{0.161} & \multirow[t]{2}{*}{0.689} \\
\hline$\nabla 3 \mathrm{~cm}$ & 38 & $24(63.2)$ & & & $23(60.5)$ & & \\
\hline \multicolumn{8}{|c|}{ Lymphnode metastasis } \\
\hline No & 62 & $26(41.9)$ & \multirow[t]{2}{*}{13.098} & \multirow[t]{2}{*}{0.000} & $25(40.3)$ & \multirow[t]{2}{*}{20.930} & \multirow[t]{2}{*}{0.000} \\
\hline Yes & 38 & $30(78.9)$ & & & $33(86.8)$ & & \\
\hline \multicolumn{8}{|l|}{ Invasion } \\
\hline No & 33 & $13(39.4)$ & \multirow[t]{2}{*}{5.512} & \multirow[t]{2}{*}{0.023} & $12(36.4)$ & 9.465 & 0.002 \\
\hline Yes & 67 & $43(67.2)$ & & & 46 (68.7) & & \\
\hline TNM stage & & & & & & & \\
\hline$\bigotimes+\square$ & 35 & $13(37.1)$ & 10.303 & 0.006 & $11(31.4)$ & 18.751 & 0.000 \\
\hline III & 38 & $22(57.9)$ & & & $24(63.2)$ & & \\
\hline IV & 27 & $21(77.8)$ & & & $23(85.2)$ & & \\
\hline Surgery & & & & & & & \\
\hline Radical & 54 & $22(40.7)$ & 12.097 & 0.002 & $22(40.7)$ & 14.371 & 0.001 \\
\hline Palliative & 36 & $28(77.8)$ & & & $28(77.8)$ & & \\
\hline
\end{tabular}




\begin{tabular}{|llllllll|}
\hline & $n$ & BIRC7 & & & STC2 & \\
\cline { 3 - 5 } & & Pos $(n, \%)$ & $\chi^{2}$ & P value & Pos $(n, \%)$ & $\chi^{2}$ & P value \\
\hline Biopsy & 10 & $6(60.0)$ & & & $8(80.0)$ & \\
\hline
\end{tabular}

The precancerous EHBT tissues were collected from 30 cases of EHCC who underwent surgery, including normal tissues $(n=12)$, mild dysplasia $(n=8) \rrbracket$ moderately dysplasia $(n=6)$ and severe dysplasia $(n=4)$. The patient age ranged from 35 to $72(48.5 \pm 9.2)$ years, including 20 males and 10 females. The biliary tract adenoma tissues collected from 10 patients ( 6 males and 4 females) who underwent surgery, the age of them ranged from 33 to $70(46.7 \pm 10.2)$ years, including 6 cases of normal tissues $\varangle 2$ cases of mild dysplasia and 2 cases of moderate to severe dysplasia. The normal biliary tract tissues ( $n=15,9$ males and 6 females) were obtained from donors of liver transplantation.

\section{Immunohistochemistry}

The tissues were routinely fixed in $4 \%$ formaldehyde solution and embedded in paraffin. Immunohistochemical staining technique using the EnVision antibody complex was performed according to the manufacturer's protocol. Briefly, formalin-fixed, paraffin-embedded tissue was cut into 4- $\mu \mathrm{m}$-thick sections, and these sections were deparaffinized and dehydrated with $3 \% \mathrm{H} 2 \mathrm{O} 2$ for $15 \mathrm{~min}$. The heat-induced epitope retrieval (HIER) was performed at $96^{\circ} \mathrm{C}$ for 30 min with sodium citrate buffer ( $10 \mathrm{mM}$ Sodium citrate, $0.05 \%$ Tween 20, $\mathrm{pH}=6.0$ ). The sections were stained by the human BIRC7 antibody (Carpentaria, CA,USA) and STC2 antibody (Carpentaria, CA,USA) for $2 \mathrm{hr}$ after washed in PBS 3 times for $5 \mathrm{~min}$ at RT. Then, the sections were incubated with $50 \mu \mathrm{L}$ Solution A (ChemMateTMEnVison+/HRP) at $37^{\circ} \mathrm{C}$ for $30 \mathrm{~min}$ and washed in PBS 3 times for $5 \mathrm{~min}$. Subsequently, DAB and haematoxylin counter-staining were conducted. Lastly, the sections were dehydrated, cleared in xylene, and mounted with neutral Canada Balsam. Ten fields were randomly selected and five hundred cells per section were independently examined by two pathologists. The average percentage of positive cells were calculated and cases with positive cells $\geq 25 \%$ were considered positive.

\section{Statistical analysis}

Comparison between groups was performed using $\chi^{2}$ test or Fisher's exact test in SPSS 17.0 (IBM Corp., USA). Kaplan-Meier univariate survival analysis and log-rank tests were performed to analyze the overall survival (OS) of patients. Cox proportional hazards regression model analysis was performed and the $95 \%$ confidence interval was calculated. Differences with P-values $<0.05$ were considered statistically significant.

\section{Results}

The expression of BIRC7 and STC2 protein in EHCC, peritumoral EHBT, EHBT adenomas and normal EHBT tissues

As showen in Fig. 1 and Fig. 2, BIRC7 and STC protein were located in the cytoplasm. In the 100 EHCC tissues, 56 and 58 of them were BIRC7 (56.0\%) and STC2 (58.0\%) positive, respectively (Table 1$)$. In the 30 peritumoral EHBT tissues, 9 and 10 of them were BIRC7 (30.0\%) and STC2 (33.3\%) positive, respectively (Table 1). In 10 EHBT adenomas, 1 and 2 of them were BIRC7 (10.0\%) and STC2 (20.0\%) positive, respectively (Table 1). In all 
15 normal EHBT tissues, the expressions of BIRC7 and STC2 were negative (Table 1). The positive rates of BIRC7 and STC2 expression in tissues obtained from peritumoral EHBT, EHBT adenomas and normal EHBT were significantly lower than those in EHCC tissues. $(P<0.05$ or $P<0.01)$.

Table 1

Different levels of BIRC7 and STC2 expression in EHCC,peritumora EHBT, EHBT adenomas and normal EHBT tissues.

\begin{tabular}{|llll|}
\hline Tissue type & $\mathbf{n}$ & BIRC 7 positive (\%) & STC2 positive (\%) \\
\hline EHCC & 100 & $56(56.0)$ & $58(58.0)$ \\
\hline Peritumoral EHBT & 30 & $9(30.0)^{\star}$ & $10(33.3)^{\star}$ \\
\hline EHBT adenomas & 10 & $1(10.0)^{\star}$ & $2(20.0)^{\star}$ \\
\hline Normal EHBT & 15 & $0(0.0)^{\star \star}$ & $0(0.0)^{\star \star}$ \\
\hline${ }^{*}, \mathrm{P}<0.05$, vs EHCC;** $\mathrm{P}<0.01$ vs EHCC. & \\
\hline
\end{tabular}

\section{The expressions of BIRC7 and STC2 protein were related to clinicopathological features of EHCC}

The expressions of BIRC7 and STC2 exhibited no significant association with clinicopathological characteristics of age, sex, tumor diameter and degree of differentiation (Table 2). However, BIRC7 and STC2 proteins were expressed at significantly higher levels in patients with lymph node metastasis, invasion of adjacent tissues, and higher TNM stage (III and/or IV) and unable to undergo resection (biopsy only). In the 100 EHCC tissues, there are 56 cases positive for BIRC7 expression, and in which 40 cases were positive for STC2 expression. There are 44 cases negative for BIRC7 expression in the $100 \mathrm{EHCC}$ tissues, and in which 26 cases were negative expression for STC2. BIRC7 expression was positively correlated with STC2 expression in $\operatorname{EHCC}\left(X^{2}=9.421, P=0.003\right)$.

\section{BIRC7 and STC2 expressions have negative impact on OS of EHCC}

Of the 100 EHCC patients, 58 patients survived no more than 12 months, 24 patients survived no more than 24 months, 10 patients survived no more than 30 months, and 12 patients who were alive at 30 months were treated as censored cases. The results indicated that the degree of differentiation, lymph node metastasis, invasion of adjacent tissues, and surgical procedure were significantly associated with the median OS of patients of EHCC $(\mathrm{P}<0.05$ or $\mathrm{P}<0.01)$ (Table 3$)$. Kaplan-Meier survival curves revealed that significantly improved OS in patients with positive-BIRC7 (Fig. 3A) or positive-STC2 (Fig. 3B) expression compared with patients of negative-BIRC7 or negative-STC2 expression, respectively. The results of Cox-proportional regression analysis were shown in Table 4, the data suggested that positive expressions of BIRC7 and STC2, along with poor differentiation of EHCC, tumor size $>3 \mathrm{~cm}$, lymph node metastasis, invasion of adjacent tissues and unable to undergo resection (biopsy only), are independent prognostic factors in EHCC (Tables 4). 
ROC analysis was performed and the area under the curve (AUC) was calculated, AUC for BIRC7 and STC2 were 0.662 (95\% Cl: $0.574-0.750)$ and 0.681 (95\% Cl: 0.594-0.768), respectively (Fig. 4). 
Table 3

Relationships between the clinicopathological characteristics, expression BIRC7 and STC2 and mean survival of patients with EHCC

\begin{tabular}{|c|c|c|c|c|}
\hline & $\mathrm{n}$ & Mean survival (month) & Chi-square & P-value \\
\hline \multicolumn{5}{|l|}{ Sex } \\
\hline Male & 61 & $12.67(3-30)$ & \multirow[t]{2}{*}{0.001} & \multirow[t]{2}{*}{0.980} \\
\hline Female & 39 & $12.59(4-30)$ & & \\
\hline \multicolumn{5}{|l|}{ Age (year) } \\
\hline$\leq 45$ & 17 & $13.82(3-30)$ & \multirow[t]{2}{*}{0.667} & \multirow[t]{2}{*}{0.414} \\
\hline$\varangle 45$ & 83 & $12.10(3-30)$ & & \\
\hline \multicolumn{5}{|c|}{ Differentiation } \\
\hline Well & 31 & $18.46(5-30)$ & \multirow[t]{3}{*}{27.655} & \multirow[t]{3}{*}{0.000} \\
\hline Moderately & 34 & $11.41(3-30)$ & & \\
\hline Poorly & 35 & $7.97(3-30)$ & & \\
\hline \multicolumn{5}{|l|}{ Tumor size } \\
\hline$\leq 3 \mathrm{~cm}$ & 62 & $12.62(3-30)$ & \multirow[t]{2}{*}{0.235} & \multirow[t]{2}{*}{0.628} \\
\hline$\otimes 3 \mathrm{~cm}$ & 38 & $12.03(5-30)$ & & \\
\hline \multicolumn{5}{|l|}{ TNM stage } \\
\hline$\nabla+\square$ & 35 & $18.57(7-30)$ & \multirow[t]{3}{*}{57.569} & \multirow[t]{3}{*}{0.000} \\
\hline III & 38 & $11.05(3-30)$ & & \\
\hline IV & 27 & $6.26(3-13)$ & & \\
\hline \multicolumn{5}{|c|}{ Lymph node metastasis } \\
\hline No & 62 & $15.52(4-30)$ & \multirow[t]{2}{*}{39.001} & \multirow[t]{2}{*}{0.000} \\
\hline Yes & 38 & $7.18(3-25)$ & & \\
\hline \multicolumn{5}{|l|}{ Invasion } \\
\hline No & 33 & $17.52(4-30)$ & \multirow[t]{2}{*}{17.399} & \multirow[t]{2}{*}{0.000} \\
\hline Yes & 67 & $9.87(3-30)$ & & \\
\hline \multicolumn{5}{|l|}{ Surgery } \\
\hline Radical & 54 & $16.62(3-30)$ & \multirow[t]{3}{*}{48.388} & \multirow[t]{3}{*}{0.000} \\
\hline Palliative & 36 & $7.58(4-24)$ & & \\
\hline Biopsy & 10 & $6.90(3-14)$ & & \\
\hline
\end{tabular}




\begin{tabular}{|lllll|}
\hline & $\mathbf{n}$ & Mean survival (month) & Chi-square & P-value \\
\hline BIRC7 & & & & \\
\hline Negative & 44 & $17.86(6-30)$ & 23.060 & 0.000 \\
Positive & 56 & $9.07(3-28)$ & & \\
STC2 & & & & \\
Negative & 42 & $18.07(5-30)$ & & 0.000 \\
Postive & 58 & $9.22(3-28)$ & & \\
\hline
\end{tabular}

Table 4

Multivariate Cox regression analysis of prognostic factors in patients with EHCC.

\begin{tabular}{|c|c|c|c|c|c|c|c|c|}
\hline & \multirow[t]{2}{*}{ Factors } & \multirow[t]{2}{*}{ B } & \multirow[t]{2}{*}{ SE } & \multirow[t]{2}{*}{ wald } & \multirow[t]{2}{*}{$\mathbf{P}$} & \multirow[t]{2}{*}{ RR } & \multicolumn{2}{|l|}{$95 \% \mathrm{Cl}$} \\
\hline & & & & & & & Lower & Upper \\
\hline $\begin{array}{l}\text { Differentiated } \\
\text { degree }\end{array}$ & Well/moderately/poorly & 0.537 & 0.154 & 12.159 & 0.000 & 1.711 & 1.265 & 2.314 \\
\hline Tumor size & $\leq 3 \mathrm{~cm} />3 \mathrm{~cm}$ & 0.530 & 0.248 & 4.567 & 0.033 & 1.699 & 1.045 & 2.762 \\
\hline $\begin{array}{l}\text { Lymph node } \\
\text { metastasis }\end{array}$ & No/yes & 0.917 & 0.295 & 9.663 & 0.002 & 2.502 & 1.403 & 4.460 \\
\hline Invasion & No/yes & 1.078 & 0.368 & 8.581 & 0.003 & 2.939 & 1.429 & 6.045 \\
\hline TNM stage & I, II/III/IV & 0.756 & 0.264 & 8.200 & 0.004 & 2.130 & 1.269 & 3.573 \\
\hline Surgery & $\begin{array}{l}\text { Radical/ Palliative/ } \\
\text { Biopsy }\end{array}$ & 0.601 & 0.188 & 10.220 & 0.001 & 1.824 & 1.262 & 2.637 \\
\hline BIRC7 & Negative /Postive & 0.912 & 0.289 & 9.959 & 0.002 & 2.489 & 1.413 & 4.386 \\
\hline STC2 & Negative /Postive & 0.740 & 0.283 & 6.837 & 0.009 & 2.096 & 1.204 & 3.650 \\
\hline
\end{tabular}

\section{Discussion}

The late-stage detection and poor outcomes of EHCC has led to an urgent need for potential biomarkers that can be applied in clinical settings[28]. To our knowledge, this is the first study that investigates BIRC7 and STC2 expression and their clinicopathological significances in EHCC. The present study demonstrated that the rate of overall positive staining with BIRC7 and STC2 was significantly increased in EHCC tumors than those in other tissues, and positive expressions of BIRC7 and STC2 were associated with progressive clinicopathological features. The study also revealed that positive-expression of BIRC7 and STC2 is an independent prognostic factor for poor outcome of EHCC.

Previous studies have demonstrated that BIRC7 plays a vital role in the development and progression of malignant tumors $[8,10-14,29-31]$. Consistent with previous studies, the present study demonstrated that 
BIRC7 expression positive positively correlated with metastasis, invasion, TNM stage, unable to undergo resection and poor prognosis. BIRC7 has specifically high expression in malignant tumor tissues and can inhibit tumor cell apoptosis in multiple way [32]. Previous study revealed knockdown of BIRC7 inhibits cell growth and invasion of gastric cancer cells through inhibiting the phosphorylation of p38 and blockade of the MAPK pathway [12]. Han Y et al. [13] showed that BIRC7 is involved in the regulation of epithelialmesenchymal transition (EMT) in breast cancer, and BIRC7 promotes the progression and metastasis of breast cancer through the regulation of EMT via the p38/GSK3 $\beta$ pathway. However, Li CJ et al. [30] revealed that BIRC7 induces EMT of breast cancer by activation of AKT signaling. The role of signaling pathways involved in the BIRC7-induced tumorigenesis and progression of EHCC requires further investigation.

Growing evidences indicated that STC2 protein played an oncogenic roles in the many carcinomas [21-27]. We found that STC2 were also associated with progressive clinicopathological features and poor prognosis in patients of EHCC. STC2 has been reported to participate in many biological events of cancer development and progression, however, the underlying mechanisms remains largely unclear[24-27, 33, 34]. Yang et al.[26] demonstrated that STC2 promotes cell proliferation, tumor growth, and metastasis through the $\mathrm{PI3K} / \mathrm{AKT} /$ Snail pathway in head and neck squamous cell carcinomas. Chen et al. [33] found that STC2 promotes colorectal cancer cells tumorigenesis and epithelial-mesenchymal transition through activating ERK/MEK and PI3K/AKT signaling pathways. A recent study suggested that STC2 silencing suppressed the migration of colorectal cancer cells and the occurrence of EMT via Wnt/ $\beta$-catenin signaling pathway [34]. Further studies are necessary in order to understand the role of STC2 played in cell proliferation, tumor growth and metastasis of EHCC.

\section{Conclusions}

In conclusion, The expression level of BIRC7 and STC2 were correlated with clinicopathological characteristics of EHCC, and positive expression of BIRC7 and STC2 are associated with progression and poor clinical outcomes of EHCC. All these findings suggest BIRC7 and STC2 can be used as a new biomarker in clinic as well as target candidate in future gene therapy.

\section{Abbreviations}

BIRC7:Baculoviral IAP repeat-containing 7; CA19-9:Carbohydrate antigen 19 - 9; CCA:Cholangiocarcinoma; EHBT:extrahepatic biliary tract; EHCC:Extrahepatic CCA; EMT:Epithelial-mesenchymal; IHCC:Intrahepatic CCA; OS:overall survival; STC2:Stanniocalcin 2.

\section{Declarations}

\section{Acknowledgments}

Non applicable.

\section{Funding}

This work was supported by the Natural Science Foundation of Hunan Province, China (Grant No. 2018JJ2561), Hunan Province Science and Technology Grant (Grant No. 2019GK5010) and National Natural 
Science Foundation of China (Grant No. 81102241)

\section{Availability of data and materials}

The data used and analyzed during the current study are available from the corresponding author on reasonable request.

\section{Authors' contributions}

LJQ carried out the experiments, data collection and analysis, manuscript preparation. YZL designed the study, funding support, and manuscript preparation and finalization. LDQ and HSF collected specimens and experimental materials. All authors read and approved the final manuscript.

\section{Ethics approval and consent to participate}

The study protocol was approved by the ethical committee of Central South University.

\section{Consent for publication}

This study is exempted from an informed consent since it is a retrospective study and the data collection and analysis were carried out without disclosing patients' identities.

\section{Competing interests}

The authors declare that they have no competing interests.

\section{References}

1. Khan SA, Tavolari S, Brandi G. Cholangiocarcinoma: Epidemiology and risk factors. Liver Int. 2019;39 Suppl 1:19-31.

2. Montomoli J, Erichsen $\mathrm{R}$, Norgaard $\mathrm{M}$, et al. Survival of patients with primary liver cancer in central and northern Denmark, 1998-2009. Clin Epidemiol. 2011;3 Suppl 1:3-10.

3. Patel T. Increasing incidence and mortality of primary intrahepatic cholangiocarcinoma in the United States. Hepatology. 2001;33:1353-7.

4. Shi Y, Deng X, Zhan Q, et al. A prospective proteomic-based study for identifying potential biomarkers for the diagnosis of cholangiocarcinoma. J Gastrointest Surg. 2013;17:1584-91.

5. Tshering G, Dorji PW, Chaijaroenkul W, et al. Biomarkers for the Diagnosis of Cholangiocarcinoma: A Systematic Review. Am J Trop Med Hyg. 2018;98:1788-97.

6. Navaneethan U, Lourdusamy V, Poptic E, et al. Comparative effectiveness of pyruvate kinase M2 in bile, serum carbohydrate antigen 19-9, and biliary brushings in diagnosing malignant biliary strictures. Dig Dis Sci. 2015;60:903-9.

7. Patel AH, Harnois DM, Klee GG, et al. The utility of CA 19-9 in the diagnoses of cholangiocarcinoma in patients without primary sclerosing cholangitis. Am J Gastroenterol. 2000;95:204-7. 
8. Chang $\mathrm{H}$, Schimmer AD. Livin/melanoma inhibitor of apoptosis protein as a potential therapeutic target for the treatment of malignancy. Mol Cancer Ther. 2007;6:24-30.

9. Kasof GM, Gomes BC. Livin, a novel inhibitor of apoptosis protein family member. J Biol Chem. 2001;276:3238-46.

10. Gazzaniga P, Gradilone A, Giuliani L, et al. Expression and prognostic significance of LIVIN, SURVIVIN and other apoptosis-related genes in the progression of superficial bladder cancer. Ann Oncol. 2003;14:85-90.

11. Vucic D, Stennicke HR, Pisabarro MT, et al. ML-IAP, a novel inhibitor of apoptosis that is preferentially expressed in human melanomas. Curr Biol. 2000;10:1359-66.

12. Ou JM, Ye B, Qiu MK, et al. Knockdown of Livin inhibits growth and invasion of gastric cancer cells through blockade of the MAPK pathway in vitro and in vivo. Int J Oncol. 2014;44:276-84.

13. Han Y, Zhang L, Wang W, et al. Livin promotes the progression and metastasis of breast cancer through the regulation of epithelialmesenchymal transition via the p38/GSK3beta pathway. Oncol Rep. 2017;38:3574-82.

14. Yang Y, Sun P, Xu W, et al. High BIRC7 Expression Might Be an Independent Prognostic Indicator of Poor Recurrence-Free Survival in Patients With Prostate Cancer. Technol Cancer Res Treat. 2018;17:1533033818809694.

15. Nachmias B, Ashhab Y, Bucholtz V, et al. Caspase-mediated cleavage converts Livin from an antiapoptotic to a proapoptotic factor: implications for drug-resistant melanoma. Cancer Res. 2003;63:6340-9.

16. Wang R, Lin F, Wang X, et al. Silencing Livin gene expression to inhibit proliferation and enhance chemosensitivity in tumor cells. Cancer Gene Ther. 2008;15:402-12.

17. Yuan B, Ran B, Wang S, et al. siRNA directed against Livin inhibits tumor growth and induces apoptosis in human glioma cells. J Neurooncol. 2012;107:81-7.

18. Oh BY, Lee RA, Kim KH. siRNA targeting Livin decreases tumor in a xenograft model for colon cancer. World J Gastroenterol. 2011;17:2563-71.

19. Sterba T, Wagner GF, Schroedter IC, et al. In situ detection and distribution of stanniocalcin mRNA in the corpuscles of Stannius of sockeye salmon, Oncorhynchus nerka. Mol Cell Endocrinol. 1993;90:179-85.

20. Ishibashi K, Miyamoto K, Taketani Y, et al. Molecular cloning of a second human stanniocalcin homologue (STC2). Biochem Biophys Res Commun. 1998;250:252-8.

21. Raulic S, Ramos-Valdes Y, DiMattia GE. Stanniocalcin 2 expression is regulated by hormone signalling and negatively affects breast cancer cell viability in vitro. J Endocrinol. 2008;197:517-29.

22. leta K, Tanaka F, Yokobori T, et al. Clinicopathological significance of stanniocalcin 2 gene expression in colorectal cancer. Int J Cancer. 2009;125:926-31.

23. Tamura K, Furihata M, Chung SY, et al. Stanniocalcin 2 overexpression in castration-resistant prostate cancer and aggressive prostate cancer. Cancer Sci. 2009;100:914-9.

24. Fang Z, Tian Z, Luo K, et al. Clinical significance of stanniocalcin expression in tissue and serum of gastric cancer patients. Chin J Cancer Res. 2014;26:602-10.

25. Zhou H, Li YY, Zhang WQ, et al. Expression of stanniocalcin-1 and stanniocalcin-2 in laryngeal squamous cell carcinoma and correlations with clinical and pathological parameters. PLoS One. 2014;9:e95466. 
26. Yang S, Ji Q, Chang B, et al. STC2 promotes head and neck squamous cell carcinoma metastasis through modulating the PI3K/AKT/Snail signaling. Oncotarget. 2017;8:5976-91.

27. Aydin HA, Toptas T, Bozkurt S, et al. Stanniocalcin-2 May Be a Potentially Valuable Prognostic Marker in Endometrial Cancer: a Preliminary Study. Pathol Oncol Res. 2019;25:751-7.

28. Marrero JA. Biomarkers in cholangiocarcinoma. Clin Liver Dis (Hoboken). 2014;3:101-3.

29. Wang L, Zhang Q, Liu B, et al. Challenge and promise: roles for Livin in progression and therapy of cancer. Mol Cancer Ther. 2008;7:3661-9.

30. Li F, Yin X, Luo X, et al. Livin promotes progression of breast cancer through induction of epithelialmesenchymal transition and activation of AKT signaling. Cell Signal. 2013;25:1413-22.

31. Liu B, Han M, Wen JK, et al. Livin/ML-IAP as a new target for cancer treatment. Cancer Lett. 2007;250:168-76.

32. Li CJ, Cong Y, Liu XZ, et al. Research progress on the livin gene and osteosarcomas. Asian Pac J Cancer Prev. 2014;15:8577-9.

33. Chen B, Zeng X, He Y, et al. STC2 promotes the epithelial-mesenchymal transition of colorectal cancer cells through AKT-ERK signaling pathways. Oncotarget. 2016;7:71400-16.

34. Li Q, Zhou X, Fang Z, et al. Effect of STC2 gene silencing on colorectal cancer cells. Mol Med Rep. 2019;20:977-84.

\section{Figures}




\section{A}
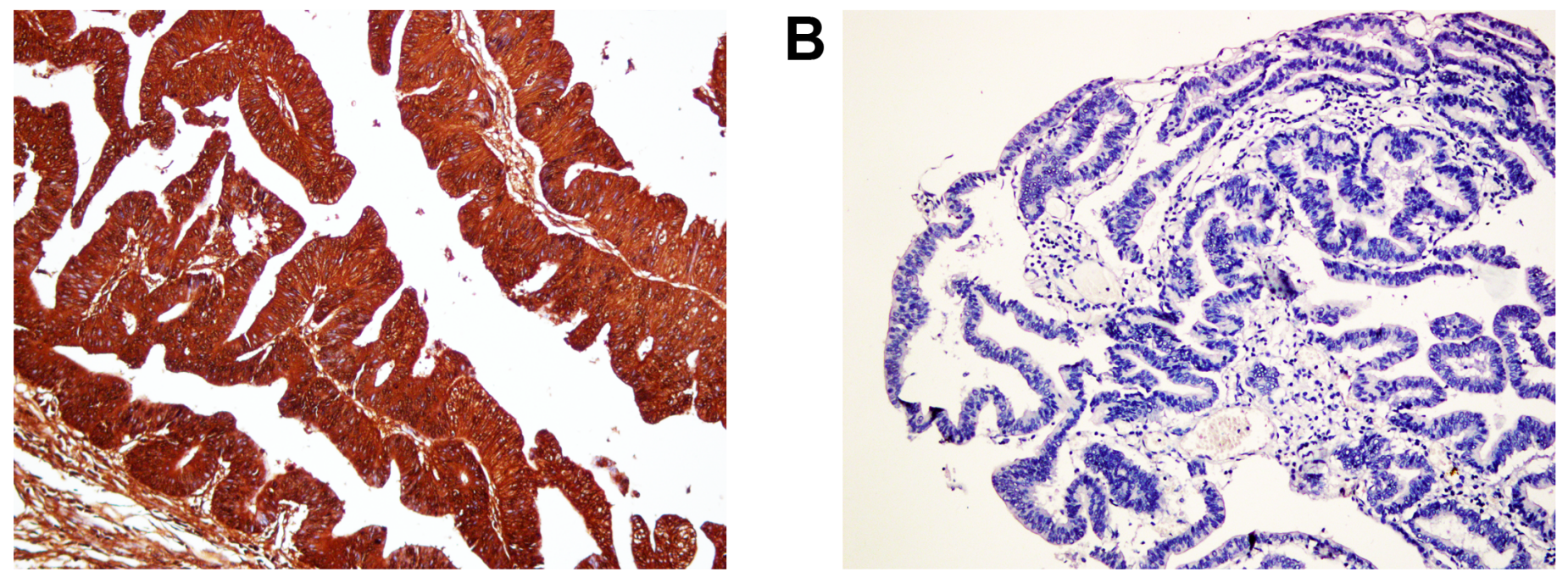

C
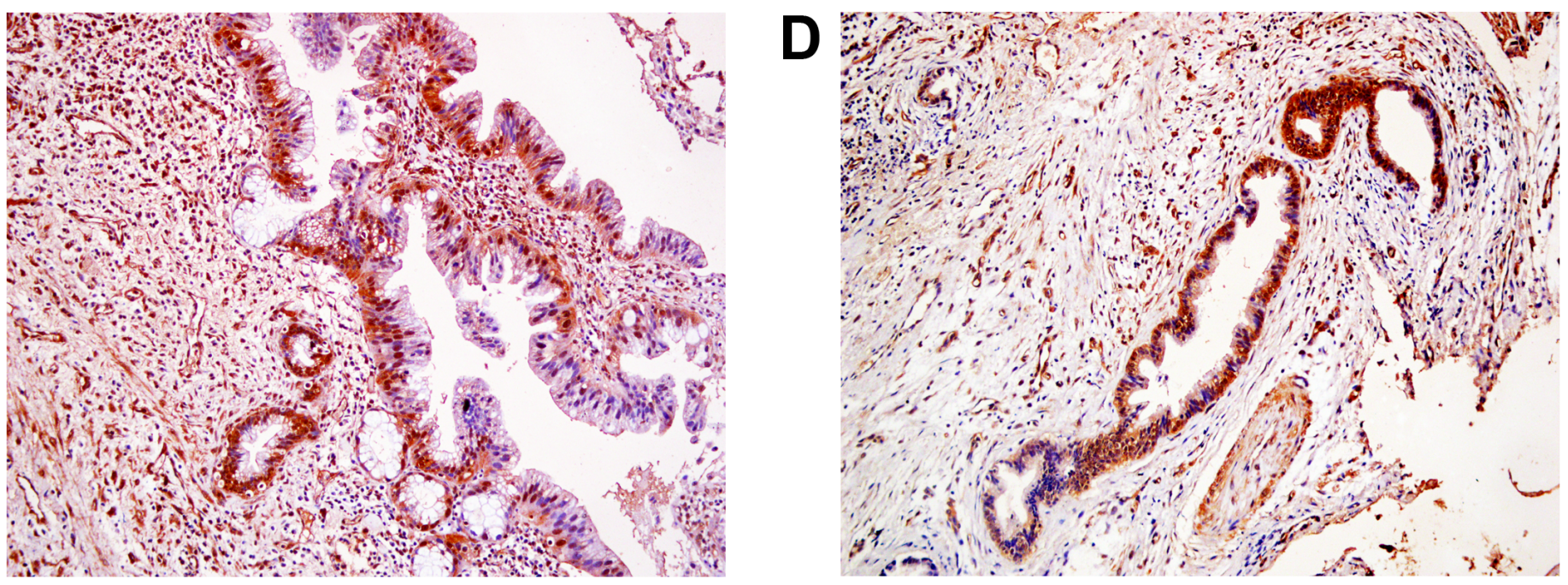

\section{Figure 1}

Representative immunohistochemical staining of BIRC7, $\times 200 \otimes$ The positive expression of BIRC7 in moderately-differentiated EHCC (A), precancerous EHBT (C) and EHBT adenomas (D) ; The negative expression of BIRC7 in well differentiated EHCC (B). 

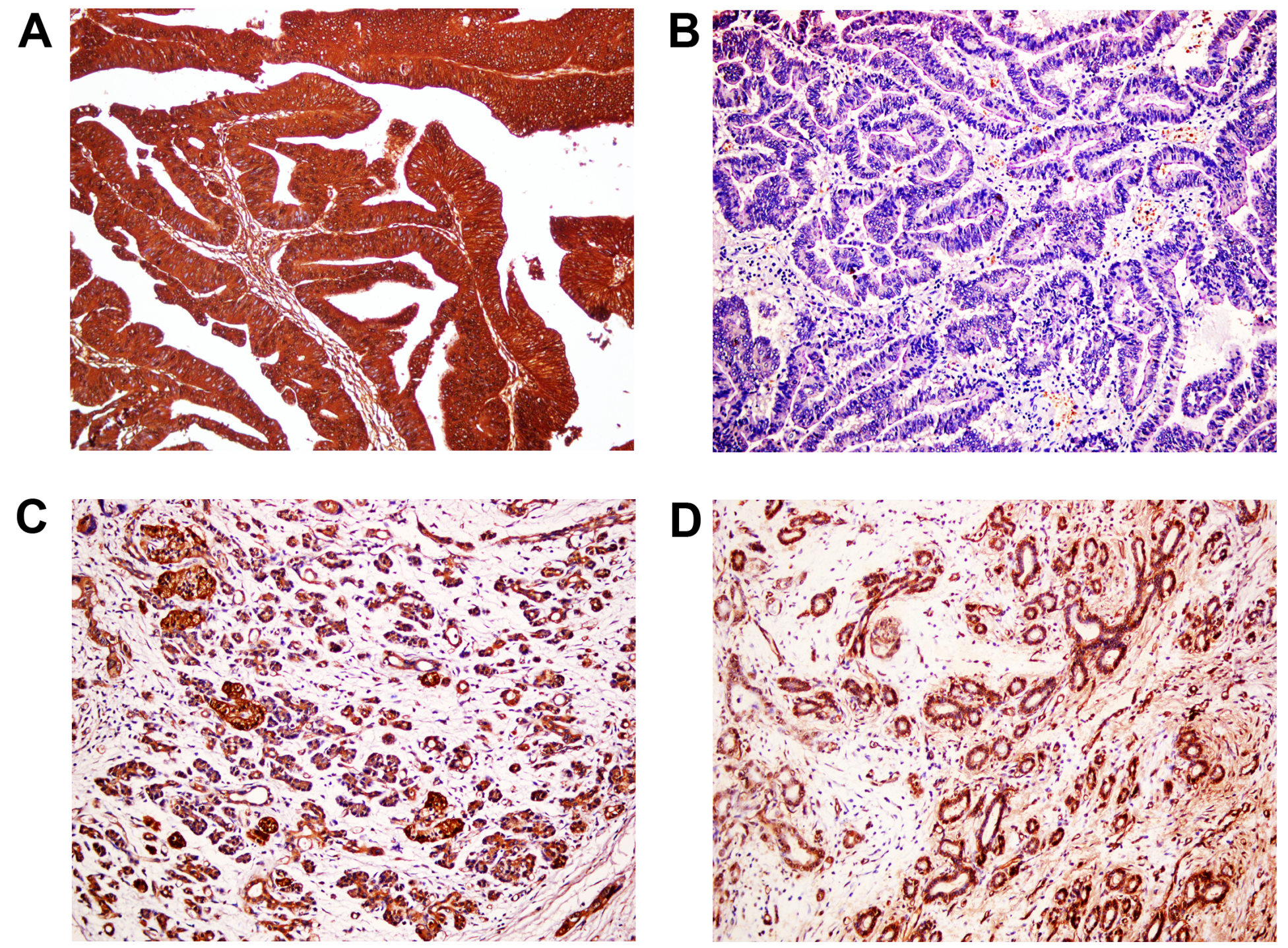

Figure 2

Representative immunohistochemical staining of STC2 $₫ \times 200 \otimes A$, The positive expression of STC2 in moderately-differentiated EHCC (A), precancerous EHBT (C) and EHBT adenomas (D); The negative expression of STC2 in well differentiated EHCC (B). 

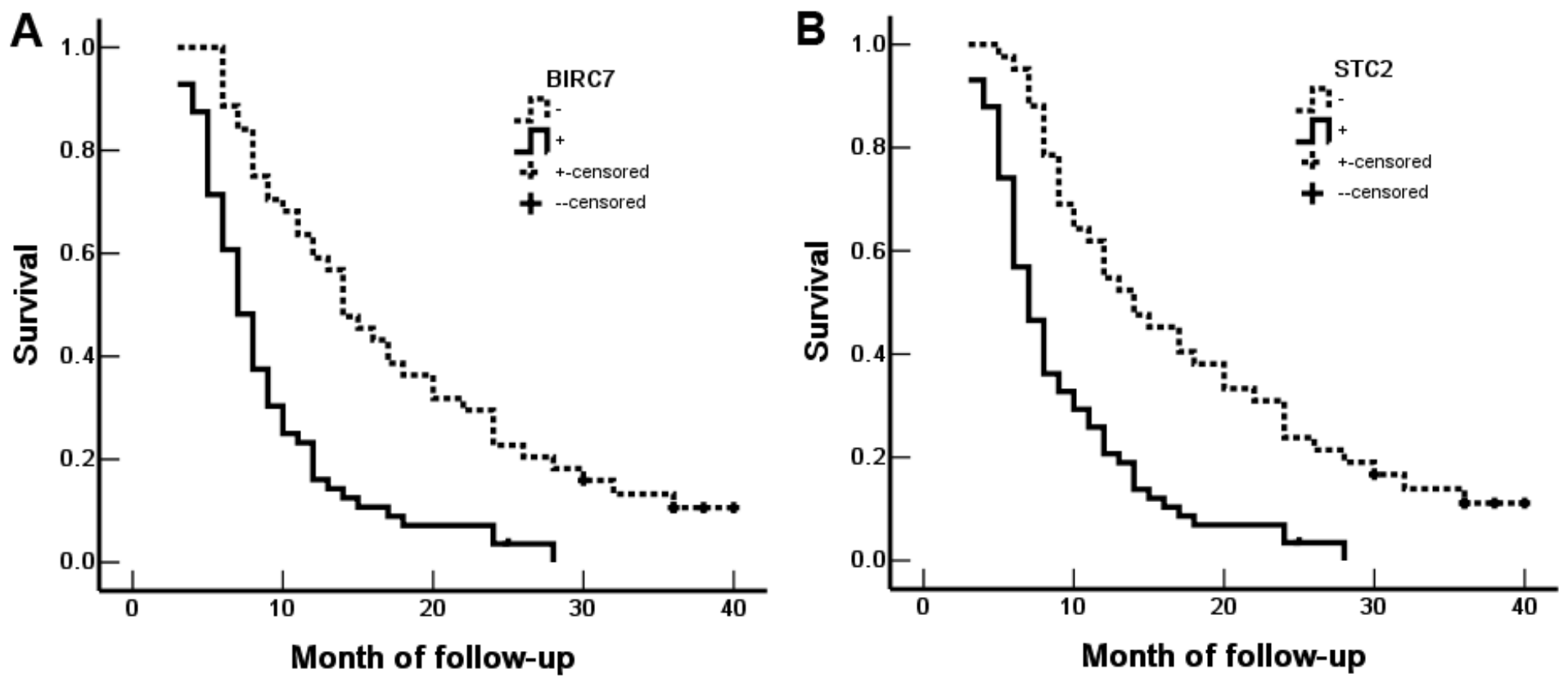

Figure 3

The correlation between the expression of BIRC7 or STC2 and OS of EHCC patients. A, The OS of EHCC patients with BIRC7-positive and BIRC7-negative expression; B, The OS of EHCC patients with STC2-positive and STC2-negative expression.

ROC Curve

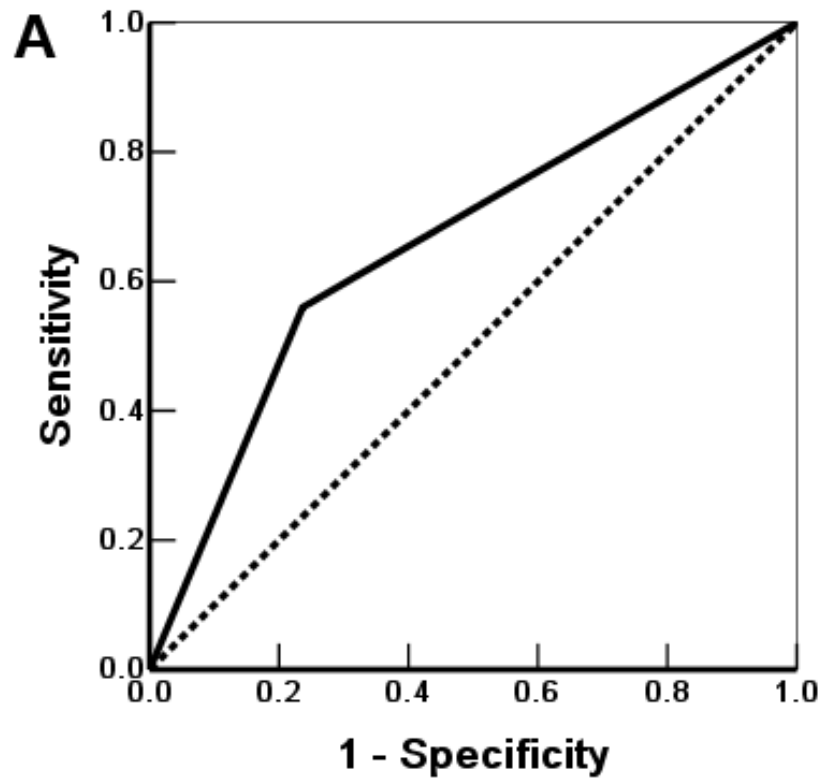

ROC Curve

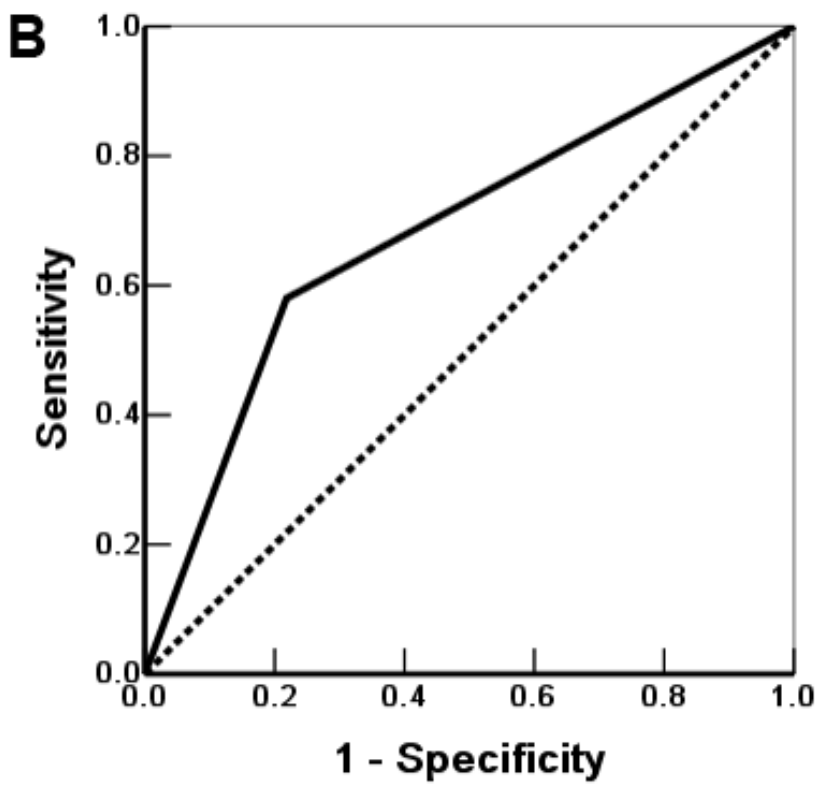

Figure 4

Multivariate analysis. ROC of Diagonal segments was produced by ties of BIRC7 (A) and STC2 (B) in EHCC patients. 